\title{
Presenting a Risk Management Model for Residential Wooden Structures in Earthquake-prone Areas of Iran
}

\author{
Bahram Mardani, ${ }^{\mathrm{a}}$ Ahmad Jahan Latibari, ${ }^{\mathrm{b}, *}$ and Ajang Tajdini ${ }^{\mathrm{c}}$ \\ A risk management model was applied to residential wooden structures in \\ earthquake-prone areas of Iran. The statistical population of the study \\ consisted of academic and organizational experts. Thirty individuals were \\ interviewed using a purposive non-random sampling technique and the \\ data adequacy and saturation principle. A semi-structured interview was \\ used to collect the required data. The validity was assessed using content \\ and construct validity. Cronbach's alpha coefficient was used to measure \\ reliability, and it was greater than 0.7 for all components. In the qualitative \\ section, data analysis was performed via a theoretical coding method that \\ used the Grounded Theory approach, and the model was presented using \\ interpretive structural modeling. The results revealed that the dimensions \\ of the seismic related risks in the implementation of wooden residential \\ structures in earthquake-prone areas of Iran, which included the internal \\ risks (employer risk, implementation risk, scheduling risk, manpower risk, \\ and design risk) and the external risk (risk due to political, economic, legal, \\ and natural factors), were the most important risks.
}

Keywords: Risk; Wooden structures; Earthquake-prone areas; Interpretive structural modelling

Contact information: a: Department of Civil Engineering, Qeshm Branch, Islamic Azad University, Qeshm, Iran; b: Department of Wood and Paper Science and Technology, Karaj Branch, Islamic Azad University, Karaj, Iran; c: Department of Wood and Paper Science and Technology, Karaj Branch, Islamic Azad University, Karaj, Iran; *Corresponding author: latibari.aj@gmail.com

\section{INTRODUCTION}

In a project environment, risk is an uncertain event or condition, such as project cost, time, or owner's quality contractor (Hillson 2002, 2009) that affects the project. Therefore, one of the primary objectives of project management is reducing project cost and time requirements and increasing the quality of work. However, both apparent and hidden potential risks that can impact cost and time are often present.

The construction of safe buildings that provide comfort, health, and economic efficiency for individuals and society has been the main objective of engineers. In addition to complying with national and technical regulations and codes, construction should be characterized by efficient and accurate implementation. Several building systems are compatible with industrial production methods, and their execution components have been developed in this context. In particular, building systems that use wooden elements have grown increasingly popular (Yeganeh and Shariatmadar 2017). The recent interest in timber construction and the application of bio-based construction products (Berge 2009) and renewable materials is due to the pursuit of more sustainable construction solutions (Calkins 2009).

Iran has experienced casualties and large economic losses due to severe earthquakes. Iran is located on the seismic belt of the Himalayan Alps, which has been the site of $21 \%$ of all earthquakes; thus, many will likely occur in the future (Aziznasiri et al. 
2017). Though wooden frames are not commonly used in residential house construction in Iran, their light structure and durability could improve resistance to earthquake stresses and adhere to the seismic codes. The seismic resistance of wood-frame houses depends primarily on the shear resistance at the base, the shear resistance of the exterior and interior walls, the uplift resistance of the building at the base, and the elevations characteristics. Based on these factors, the most important advantage of wooden structures is their high resistance to natural disasters, such as earthquakes. The high damping coefficient of wood makes it the most suitable type of material for earthquake-resistant structures and reduces the dead load of the building up to seven times compared to steel and concrete. Thus, wooden structures are among the best earthquake resistant systems. Further, wooden buildings can adapt to different climatic conditions.

Lightweight structures allow faster construction and return on investment. The excellent insulation, notably reduced energy consumption, long life, beauty, adaptability to different climates, and lack of construction debris make wood an attractive material for house construction (Purkus et al. 2018).

Abedini and Karimi (2018) studied seismic risk assessment in the city of Urmia using the Fuzzy analytical hierarchy process (FAHP) method, and they found that the highest coefficient of importance of the indicators was related to the number of floors, whereas the lowest was related to the household index in the residential unit. Aziznasiri et al. (2017) found that the consideration of location in an earthquake-prone area, the type of structural material, building design, building age, design standard and codes, number of floors, type of roof, type of soil, and risk densities are the main factors of utmost importance. Li and Ellingwood (2009) reported that structural reliability-based methods, which evaluate potential natural hazards and structural system responses, are essential to determining the expected casualties from natural disasters and developing appropriate management strategies. This framework allows the main sources of uncertainty that affect building performance to be identified and provides insight into methods of reducing several hazards.

Numerous studies have applied the International Safety Management (ISM) methodology in risk assessment. Wu et al. (2015) conducted risk assessments of offshore pipeline projects by systematically integrating ISM and the Bayesian Network (BN). The final stage of risk assessment was to perform a risk evaluation using the $\mathrm{BN}$ in two cases in Taiwan. The results revealed that the $\mathrm{BN}$ can provide explicit risk information to support better project management. Faisal et al. (2006) used ISM to understand the influences of various performance variables in the supply chain and to analyze an effective supply chain risk mitigation strategy. Ahmad et al. (2019), for identification of effective Factors of Seismic Soil Liquefaction, applied the ISM and MICMAC analysis. The results provided accurate procedure of selecting influential factors for the establishment of seismic soil liquefaction potential and liquefaction-induced hazards risk assessment models.

There has yet to be a risk management study on the use of wooden residential structures in earthquake-prone areas of Iran. Therefore, this study aimed to (1) identify the factors that contribute to risk management in residential wooden structures in earthquakeprone areas of Iran, (2) compare the factors that contribute to risk management in wooden residential structures in earthquake-prone areas of Iran, (3) provide a model for risk management in residential wooden structures in earthquake-prone areas of Iran, and (4) propose mitigation actions for the risks identified in residential wooden structures in earthquake-prone areas of Iran. 


\section{EXPERIMENTAL}

\section{Materials}

This study employed a mixed research method in terms of implementation process, and it was a descriptive-survey study in terms of research objectives. The data collection tools in the qualitative section were an open questionnaire via the Delphi method and interviewing. A purposive non-random sampling technique was used to select the sample. The Delphi method is based on expert opinion on predicting the future most accurately. Thus, unlike survey research methods, the validity of the Delphi method depends not just on the number of participants in the research but also emphasizes the scientific validity of the experts participating in the research. Delphi is a series of survey rounds or questionnaires that after evaluating the initial questionnaire, the subsequent questionnaires for following evaluation rounds are formed (van Teijlingen et al. 2006). For the initial continuum question, focused and broad questions (usually broad and open reply) are used. However, when the participant's guidance is on a specific topic, focused and structured questions are used (Landeta 2006). With this method, feedback provides the opportunity to review one's own opinions and allows experts to evaluate the opinions of others, which is an important part of moving towards consensus (Rowe and Wright 1999). Therefore, participants are encouraged and allowed to reconsider their judgments from previous rounds. However, the exchange of information between professionals is not free (Powell 2003).

In this study, 30 specialized participants who were academic and construction engineering organization experts were nominated to respond, and sampling met the validity requirements. To validate the content of the Delphi researcher-made questionnaire, the field experts and professionals with expertise in the field of risk management on the use of wooden residential structures were nominated. Cronbach's alpha coefficient was used to measure reliability. According to the Cronbach's alpha coefficient (0.93), the reliability of the questionnaire items and the coherence of the answers are confirmed if the alpha value is greater than its minimum value (0.7), which was the case in this study. Finally, a research questionnaire with 43 indicators was obtained, which was divided into two categories of internal risks and external risks. Van Thuyet et al. (2007) classified the source of risks in projects as internal and external risks. Internal risks are inherent risks in a project and may be under control of the project manager, which cause uncertainty that may affect the project and External risks are out of the project manager's control but may affect the direction of the project. The conceptual model of the research is presented in the Fig. 1. Quantitative data analysis using MAXQDA software (2018 version) was used to encode concepts derived from interviews with experts, and interpretive structural modeling was employed. MAXQDA software is being developed and distributed by VERBI Software Company based in Berlin, Germany. 


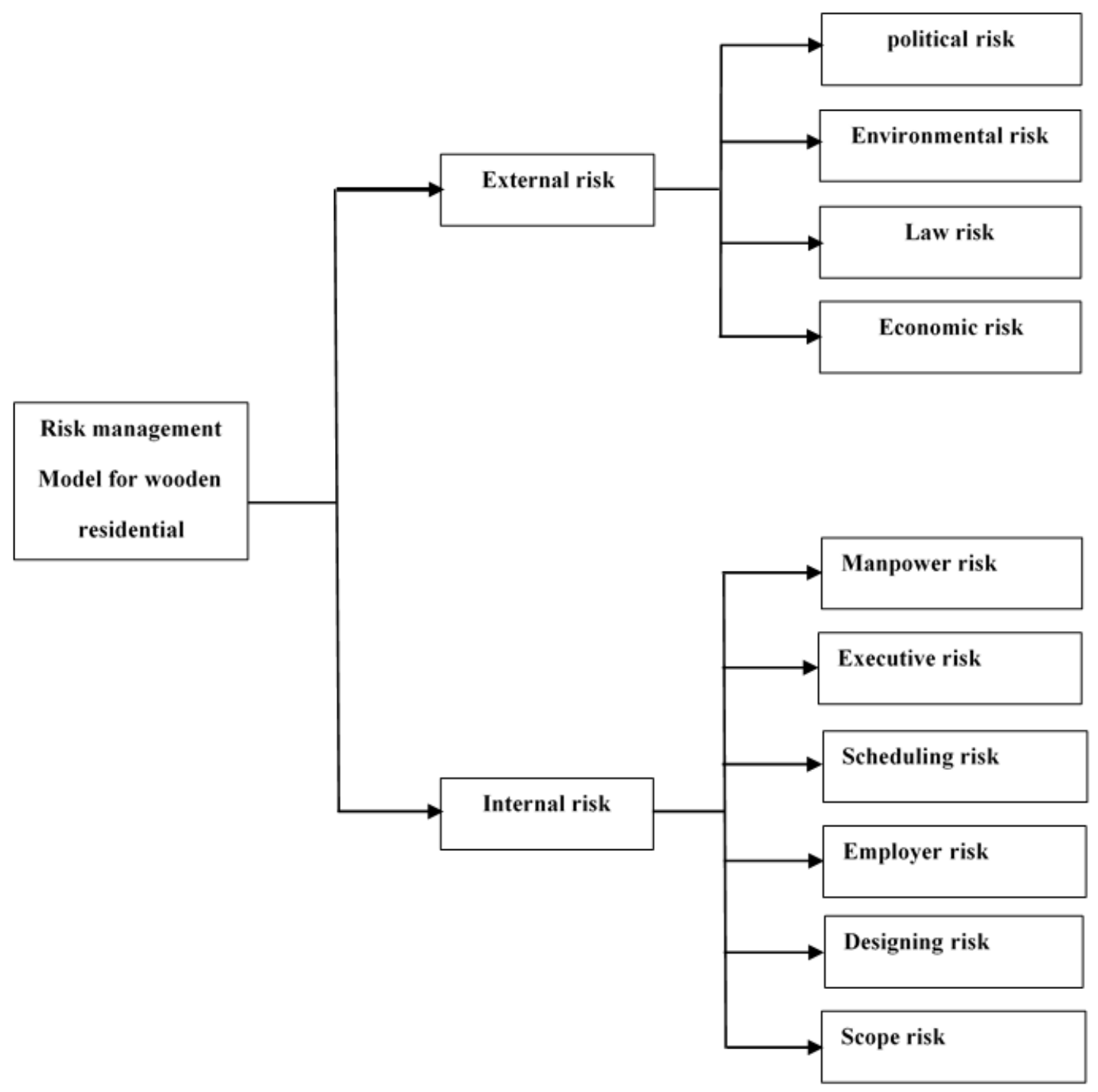

Fig. 1. Conceptual model

\section{Methods}

The Delphi method and interpretive structural modeling (ISM) were used to collect the required data. ISM is an interactive learning process in which a set of different and interrelated elements are structured in a comprehensive systematic model. This methodology helps create and direct complex relationships between the elements of a system (Faisal et al. 2006). The ISM methodology was developed by Warfield (1974) and Sage (1977) to identify the contextual relations between previously identified factors, criteria, or variables. Interpretive structural modeling is a qualitative tool developed by experts, and it has been used by researchers in several areas of knowledge. In particular, it has been applied in research on environmental management, quality management, logistics, and supply chain management. The aim of ISM is to identify and analyze the interactions between the factors studied (Govindan et al. 2012; Tan et al. 2019; Dhir 2020). This method is based on the reasoning that the elements that have a greater impact on other elements in a system are more important. The model obtained using this methodology 
shows the structure of a complex problem or issue, system, or field of study (Faisal et al. 2006). Therefore, this method was used to evaluate the effectiveness of the components and determine their priority.

\section{RESULTS}

Thirty open questionnaires were distributed among the experts, and the research concepts were extracted from the questionnaires via the Delphi method. The results of the coding are summarized in Table 1.

Table 1. Open, Axial, and Selective Coding

\begin{tabular}{|c|c|c|c|}
\hline Construct & $\begin{array}{c}\text { Selective } \\
\text { Coding }\end{array}$ & Axial Coding & Open Coding \\
\hline \multirow{32}{*}{ 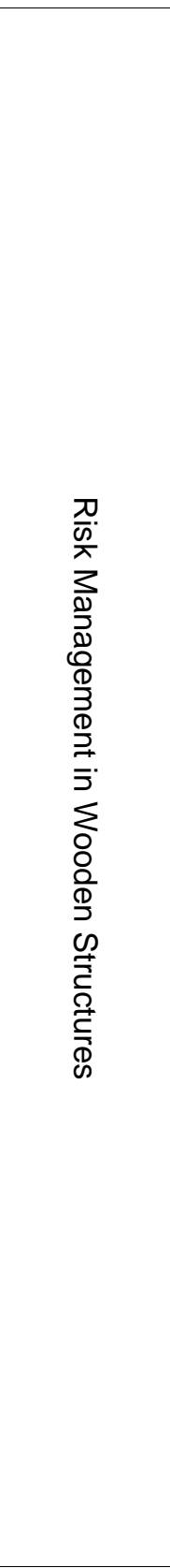 } & \multirow{15}{*}{ 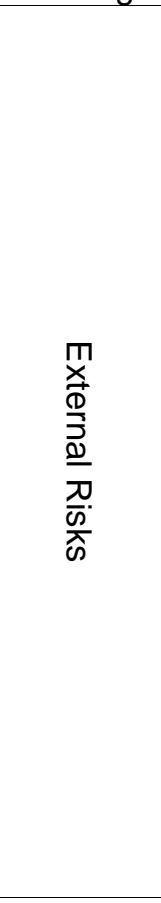 } & \multirow{4}{*}{ Political Risk } & $\begin{array}{c}\text { Emergence of political pressures and sanctions } \\
\text { (affecting procurement, financing, use of foreign } \\
\text { forces, etc.) }\end{array}$ \\
\hline & & & Domestic and foreign policy developments \\
\hline & & & $\begin{array}{l}\text { Occurrence of political events (war, revolution, coup, } \\
\text { etc.) }\end{array}$ \\
\hline & & & $\begin{array}{l}\text { Lack of access to foreign advisers due to political } \\
\text { issues }\end{array}$ \\
\hline & & \multirow{3}{*}{$\begin{array}{l}\text { Environmental } \\
\text { Risk }\end{array}$} & Natural force events such as earthquakes \\
\hline & & & $\begin{array}{l}\text { Unpredictable physical conditions such as fire and } \\
\text { explosion }\end{array}$ \\
\hline & & & Limited access due to security permits and traffic \\
\hline & & \multirow{3}{*}{ Legal Risk } & Lack of local and regional regulations \\
\hline & & & Providing permits and approvals \\
\hline & & & $\begin{array}{c}\text { Litigation and environmental standards and } \\
\text { requirements }\end{array}$ \\
\hline & & \multirow{5}{*}{$\begin{array}{l}\text { Economic } \\
\text { Risk }\end{array}$} & Unrealistic cost \\
\hline & & & Incomplete cost plan \\
\hline & & & $\begin{array}{l}\text { Lack of cost control during design and } \\
\text { implementation }\end{array}$ \\
\hline & & & Exchange rate fluctuations and inflation \\
\hline & & & Financial and budget bankruptcy \\
\hline & \multirow{17}{*}{$\begin{array}{l}\bar{D} \\
\frac{\bar{D}}{\bar{D}} \\
\frac{D}{D} \\
\frac{D}{0} \\
\frac{\omega}{\hat{\omega}}\end{array}$} & \multirow{3}{*}{$\begin{array}{l}\text { Manpower } \\
\text { Risk }\end{array}$} & $\begin{array}{l}\text { Low skills of labor force in the construction of } \\
\text { wooden structures }\end{array}$ \\
\hline & & & $\begin{array}{l}\text { Low acceptance of labor to construct wooden } \\
\text { structures compared to concrete }\end{array}$ \\
\hline & & & Worker injuries \\
\hline & & \multirow{3}{*}{$\begin{array}{l}\text { Scheduling } \\
\text { Risk }\end{array}$} & Uncertainty of restrictions \\
\hline & & & Lack of proper planning \\
\hline & & & Failing to consider all activities in the schedule \\
\hline & & \multirow{6}{*}{$\begin{array}{l}\text { Executive } \\
\text { Risk }\end{array}$} & Non-compliance with technical and safety standards \\
\hline & & & Improper execution methods \\
\hline & & & Complexity of project implementation and rework \\
\hline & & & Failure of contractors \\
\hline & & & Deficiencies in executive plans \\
\hline & & & Incidence of fatal accidents \\
\hline & & \multirow{5}{*}{$\begin{array}{l}\text { Procurement } \\
\text { Risk }\end{array}$} & Lack of access to equipment \\
\hline & & & Delay in procurement of materials and equipment \\
\hline & & & Defects in equipment \\
\hline & & & Lack of foreign suppliers \\
\hline & & & Shortage of required materials \\
\hline
\end{tabular}




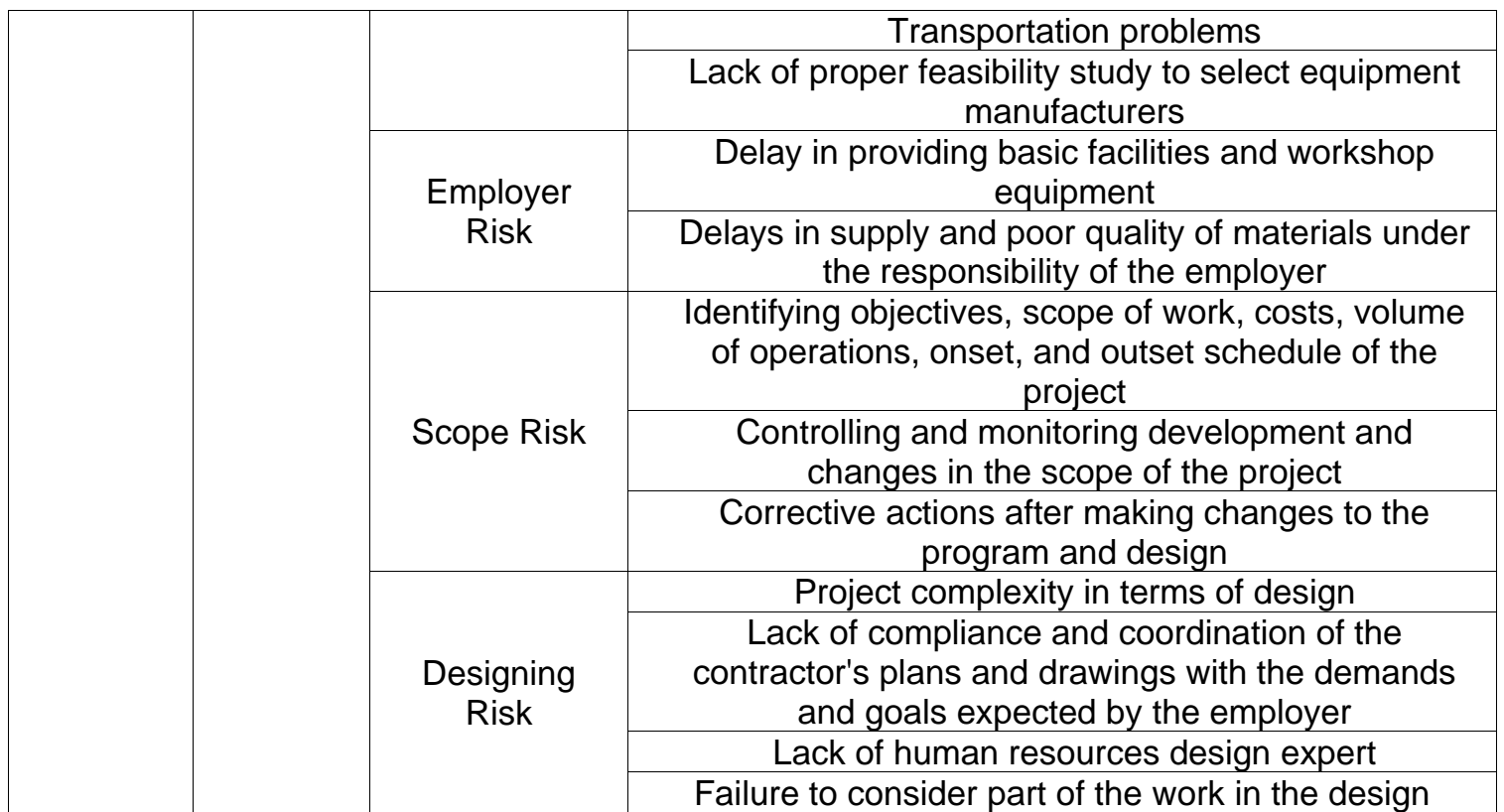

A total of 43 indicators were identified from the opinions of respondents and the literature. These indicators were refined via another questionnaire, and 11 components ultimately remained (Table 2 ).

Table 2. Final and Effective Factors on Risk Management in Wooden Residential Structures in Earthquake-prone Areas of Iran

\begin{tabular}{|c|c|}
\hline No. & Risk Factor \\
\hline 1 & Unpredictable physical conditions and natural hazards \\
\hline 2 & $\begin{array}{c}\text { Political pressures and sanctions affecting procurement, financing, use of foreign force, } \\
\text { etc. }\end{array}$ \\
\hline 3 & $\begin{array}{l}\text { Failure to properly allocate financial resources and budgets and changes in exchange } \\
\text { rates and inflation }\end{array}$ \\
\hline 4 & Lack of skilled labor for the construction of wooden structures \\
\hline 5 & Failure to consider local regulations and permits \\
\hline 6 & Complexity of wooden structure construction and rework \\
\hline 7 & $\begin{array}{l}\text { Inconsistency and lack of coordination between the plans and maps of the contractor } \\
\text { and the employer and the lack of human resources for wood design specialists }\end{array}$ \\
\hline 8 & $\begin{array}{c}\text { Occurrence of defects in the procurement of equipment for wooden structure } \\
\text { construction }\end{array}$ \\
\hline 9 & $\begin{array}{c}\text { Lack of control and monitoring of development and changes in the scope of wooden } \\
\text { structure construction work }\end{array}$ \\
\hline 10 & Lack of proper time planning for the construction of wooden structures \\
\hline 11 & $\begin{array}{l}\text { Delays in supply and poor quality of equipment and the materials under the employer's } \\
\text { commitment }\end{array}$ \\
\hline
\end{tabular}


In the next step, the contextual relationship between the factors was determined. The contextual relationships indicate whether or not one factor leads to another. For this purpose, a structural self-interaction matrix (SSIM) was developed based on the opinion of the experts, which indicated a pair-wise relationship between the factors that affected risk management in residential wooden structures in earthquake-prone areas of Iran (Table 3). This matrix indicated the need to specify the direction of the relationship (if any) between any two factors. In this matrix, four symbols are used as follows: V: the relation from row (i) to column (j); A: the relation from $\mathrm{j}$ to $\mathrm{I}$; $\mathrm{X}$ : the relation from $\mathrm{i}$ to $\mathrm{j}$ and $\mathrm{j}$ to $\mathrm{I}$; and $\mathrm{O}$ : there is no relationship between $\mathrm{i}$ and $\mathrm{j}$ (Ertas et al. 2015).

Table 3. Structural Self-Interaction Matrix (SSIM)

\begin{tabular}{|c|c|c|c|c|c|c|c|c|c|c|c|}
\hline 11 & 10 & 9 & 8 & 7 & 6 & 5 & 4 & 3 & 2 & 1 & Factors \\
\hline $\mathrm{A}$ & $\mathrm{O}$ & $\mathrm{A}$ & $\mathrm{A}$ & $\mathrm{A}$ & $\mathrm{V}$ & $\mathrm{O}$ & $\mathrm{A}$ & $\mathrm{A}$ & $\mathrm{A}$ & $\mathrm{X}$ & 1 \\
\hline $\mathrm{A}$ & $\mathrm{O}$ & $\mathrm{O}$ & $\mathrm{V}$ & $\mathrm{A}$ & $\mathrm{V}$ & $\mathrm{O}$ & $\mathrm{A}$ & $\mathrm{A}$ & $\mathrm{X}$ & & 2 \\
\hline $\mathrm{V}$ & $\mathrm{O}$ & $\mathrm{V}$ & $\mathrm{V}$ & $\mathrm{A}$ & $\mathrm{V}$ & $\mathrm{O}$ & $\mathrm{X}$ & $\mathrm{X}$ & & & 3 \\
\hline $\mathrm{V}$ & $\mathrm{V}$ & $\mathrm{V}$ & $\mathrm{V}$ & $\mathrm{X}$ & $\mathrm{V}$ & $\mathrm{O}$ & $\mathrm{X}$ & & & & 4 \\
\hline $\mathrm{O}$ & $\mathrm{O}$ & $\mathrm{O}$ & $\mathrm{O}$ & $\mathrm{O}$ & $\mathrm{V}$ & $\mathrm{X}$ & & & & & 5 \\
\hline $\mathrm{A}$ & $\mathrm{A}$ & $\mathrm{A}$ & $\mathrm{A}$ & $\mathrm{A}$ & $\mathrm{X}$ & & & & & & 6 \\
\hline $\mathrm{X}$ & $\mathrm{V}$ & $\mathrm{V}$ & $\mathrm{V}$ & $\mathrm{X}$ & & & & & & & 7 \\
\hline $\mathrm{A}$ & $\mathrm{O}$ & $\mathrm{V}$ & $\mathrm{X}$ & & & & & & & & 8 \\
\hline $\mathrm{A}$ & $\mathrm{O}$ & $\mathrm{X}$ & & & & & & & & & 9 \\
\hline $\mathrm{A}$ & $\mathrm{X}$ & & & & & & & & & & 10 \\
\hline $\mathrm{X}$ & & & & & & & & & & & 11 \\
\hline
\end{tabular}

Based on the SSIM, a binary matrix (elements are 0 or 1 ) is created that reflects the directed relationships between the factors. The initial reachability matrix was developed from the SSIM, and the matrix was then checked for transitivity. After incorporating the transitivity, the final reachability matrix was obtained (Table 4). The transitivity of the contextual relation is a basic assumption in ISM, which states that if element $\mathrm{A}$ is related to element $\mathrm{B}$, and $\mathrm{B}$ is related to $\mathrm{C}$, then $\mathrm{A}$ is necessarily related to $\mathrm{C}$.

Table 4. Final Reachability Matrix

\begin{tabular}{|c|c|c|c|c|c|c|c|c|c|c|c|c|}
\hline & 1 & 2 & 3 & 4 & 5 & 6 & 7 & 8 & 9 & 10 & 11 & Influence \\
\hline 1 & 1 & 0 & 0 & 0 & 0 & 1 & 0 & 0 & 0 & 0 & 0 & 2 \\
\hline 2 & 1 & 1 & 0 & 0 & 0 & 0 & 0 & 1 & $1^{*}$ & 0 & 0 & 4 \\
\hline 3 & 1 & $1^{*}$ & 1 & 1 & 0 & 1 & $1^{*}$ & 1 & 1 & $1^{*}$ & 1 & 10 \\
\hline 4 & 1 & 1 & 1 & 1 & 0 & 1 & 1 & 1 & 1 & 1 & 1 & 10 \\
\hline 5 & 0 & 0 & 0 & 0 & 1 & 1 & 0 & 0 & 0 & 0 & 0 & 2 \\
\hline 6 & 0 & 0 & 0 & 0 & 0 & 1 & 0 & 0 & 0 & 0 & 0 & 1 \\
\hline 7 & 1 & 1 & 1 & 1 & 0 & 0 & 0 & $1^{*}$ & 1 & 1 & 1 & 8 \\
\hline 8 & 1 & 0 & 0 & 0 & 0 & 1 & 0 & 1 & 1 & 0 & 0 & 4 \\
\hline 9 & 1 & 0 & 0 & 0 & 0 & 1 & 0 & 0 & 1 & 0 & 0 & 3 \\
\hline 10 & 0 & 0 & 0 & 0 & 0 & 1 & 0 & 0 & 0 & 1 & 0 & 2 \\
\hline 11 & 1 & 1 & $1^{*}$ & $1^{*}$ & 0 & 1 & 1 & 1 & $1^{*}$ & 1 & 1 & 10 \\
\hline Dependence & 8 & 5 & 4 & 4 & 1 & 9 & 3 & 6 & 7 & 5 & 4 & \\
\hline
\end{tabular}

The reachability and antecedent sets (Warfield 1974) for each factor were obtained from the final reachability matrix. The reachability set for a particular factor consists of the factor itself and the other factors that it influences. The antecedent set consists of the factor itself and the other factors that may influence it. Subsequently, the intersection of these sets 
is derived for all variables. The variable for which the reachability and intersection sets are the same is given the top-level variable in the ISM hierarchy, which would not help achieve any other variable above their own level (Parthiban et al. 2012). After the top-level factor was identified, it was discarded from further hierarchical analysis by removing the factor from all sets. For example, Table 5 shows that factor 6 was found at level 1 due to similar reachability and intersection sets. Thus, it was positioned at the top of the ISM hierarchy. Factor 6 was then removed from all sets for further analysis, as its level had been obtained. This iteration was repeated until the levels of each factor were discovered. These results revealed that there were six levels of effectiveness in the study of factors affecting risk management in residential wooden structures in earthquake-prone areas of Iran. The identified levels aided in the establishment of the digraph and the final model of ISM. Due to the large number of the iteration tables in this section, only Table 5 is presented for level 1. Finally, six levels were identified, and the factors associated with each level shown in Fig. 2 were as follows:

- Level 1: Factor 6 (complexity of wooden structure construction and rework).

- Level 2: Factor 1 (lack of proper time planning for the construction of wooden structures), Factor 5 (failure to consider local regulations and permits), and Factor 10 (unpredictable physical conditions and natural disasters).

- Level 3: Factor 9 (lack of control and monitoring of development and changes in the scope of wooden structure construction work).

- Level 4: Factor 2 (political pressures and sanctions that affect procurement, financing, employment of foreign forces, etc.), and Factor 8 (occurrence of defects in the procurement of equipment for wooden structure construction).

- Level 5: Factor 7 (inconsistency and lack of coordination between the plans and maps of the contractor and the employer and the lack of human resources for wood design specialists).

- Level 6: Factor 3 (failure to properly allocate financial resources and budgets and changes in exchange rates and inflation), Factor 4 (lack of skilled labor for the construction of wooden structures), and Factor 11 (delays in supply and poor quality of equipment and the materials under the employer's commitment).

Table 5. Iteration 1

\begin{tabular}{|c|c|c|c|c|}
\hline Factors & Reachability Set & Antecedent Set & Intersection Set & Level \\
\hline 1 & $(1,6)(1,6)$ & $(11,9,8,7,4,3,2,1)$ & $(1)$ & \\
\hline 2 & $(9,8,2,1)$ & $(11,7,4,3,2)$ & $(2)$ & \\
\hline 3 & $(11,10,9,8,7,6,4,3,2,1)$ & $(11,7,4,3)$ & $(11,7,4,3)$ & \\
\hline 4 & $(11,10,9,8,7,6,4,3,2,1)$ & $(11,7,4,3)$ & $(11,7,4,3)$ & \\
\hline 5 & $(6,5)$ & $(5)$ & $(5)$ & \\
\hline 6 & $(6)$ & $(11,10,9,8,6,5,4,3,1)$ & $(6)$ & 1 \\
\hline 7 & $(11,10,9,8,4,3,2,1)$ & $(11,4,3)$ & $(11,4,3)$ & \\
\hline 8 & $(9,8,6,1)$ & $(11,8,7,4,3,2)$ & $(8)$ & \\
\hline 9 & $(9,6,1)$ & $(11,9,8,7,4,3,2)$ & $(9)$ & \\
\hline 10 & $(10,6)$ & $(11,10,7,4,3)$ & $(10)$ & \\
\hline 11 & $(11,10,9,8,7,6,4,3,2,1)$ & $(11,7,4,3)$ & $(11,7,4,3)$ & \\
\hline
\end{tabular}




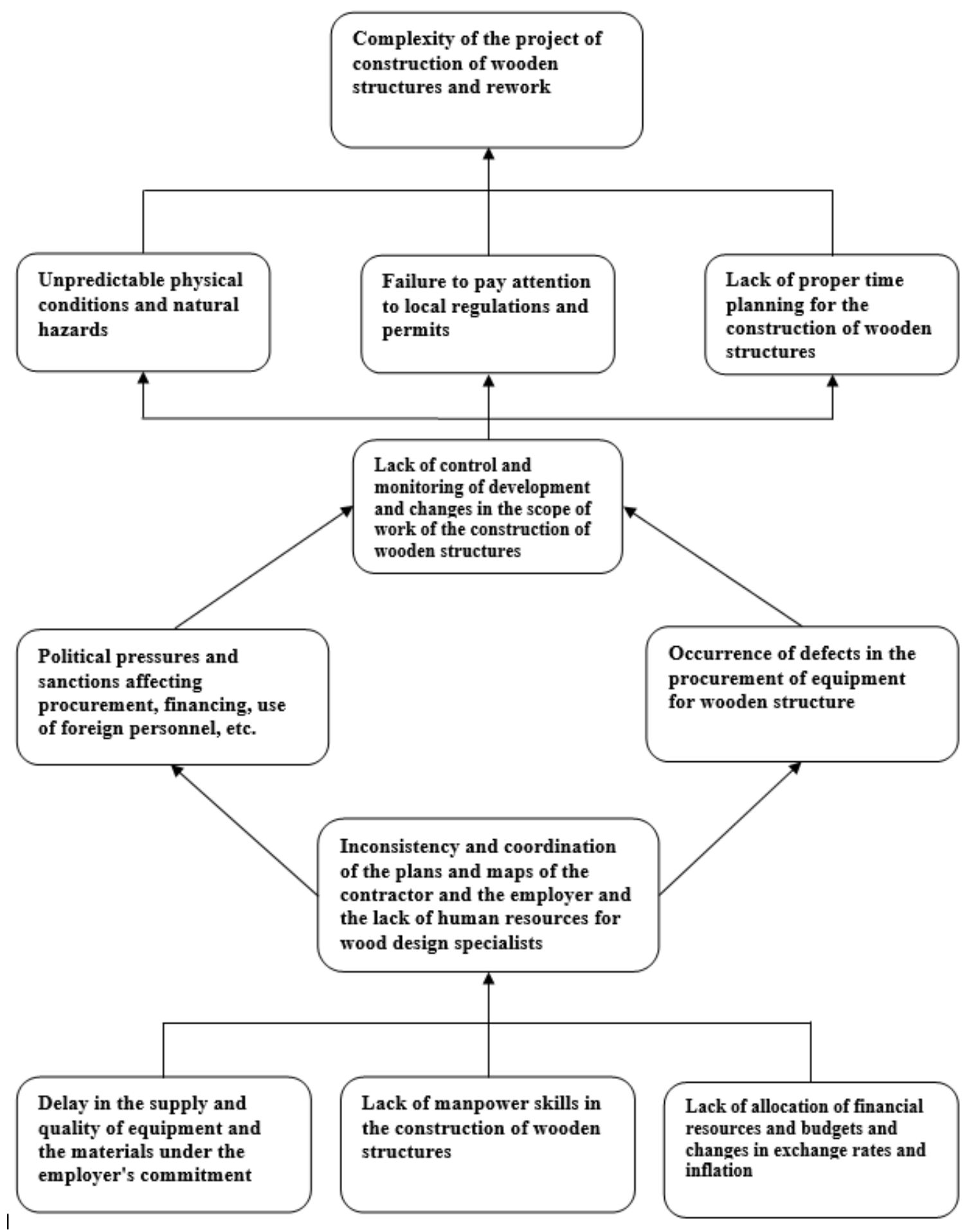

Fig. 2. ISM based model of the factors that impact risk management in residential wooden structures in earthquake-prone areas of Iran 
Then, MICMAC was employed to study the diffusion of impacts through reaction paths and loops to develop hierarchies for members of an element set. Warfield (1990) found that MICMAC analysis can be used to identify and analyze the elements in a complicated system. Generally, the elements are classified into 4 clusters of autonomous, dependent, linkage, and independent (driver) sources according to the driving power and dependencies of all the elements (Ravi and Shankar 2005). The objective of MICMAC analysis is to analyze the driving power and the dependence of the elements (Mandal and Deshmukh 1994; Faisal et al. 2007).

In MICMAC analysis, factors are divided into four clusters with respect to the driving power and dependence power. These clusters are: Cluster I: Autonomous Factors, which are relatively cut off from the system and had weak driving power and weak dependence; Cluster II: Dependent Factors, which had weak driving power but strong dependence, so are primarily dependent of other factors; Cluster III: Linkage factors with strong driving power and strong dependence. These factors were unstable because any change that occurred to them had an effect on others; and Cluster IV: Independent Factors, which had strong driving power but weak dependence (Ahmad et al. 2019).

Classification of the dimensions that affected the implementation of risk management in wooden residential structures in earthquake-prone areas of Iran is shown in Fig. 3. The aim of the classification of the factors was to analyze the driver power and dependency of factors (Jharkharia and Shankar 2005). Generally, high factor driver power means that a large number of factors could be easily removed. Higher dependence values for factors require a large set of factors to be addressed before their removal. The classification of the effective factors within the four clusters helps identify the potential difficulty of removing the factors.

Among the factors under consideration in this study, three factors are used in Autonomous area, which are, 1-factor2: political pressures and sanctions affecting procurement, financing, use of foreign force, etc., 2- factor 5: failure to consider local regulations and permits and factor and 3- factor10: Lack of proper time planning for the construction of wooden structures. Also, among the factors under study, there are four factors in dependent area, 1-factor1: unpredictable physical conditions and natural hazards, 2-factor 6: complexity of wooden structure construction and rework, 3-factor 8: occurrence of defects in the procurement of equipment for wooden structure construction and factor, and 4- factor 9 is lack of control and monitoring of development and changes in the scope of wooden structure construction work. Furthermore, among the factors studied in this study, none of them are in linkage area.

There are four factors in independent area, which are, 1-factor 3: failure to properly allocate financial resources and budgets and changes in exchange rates and inflation, 2factor 4: lack of skilled labor for the construction of wooden structures, 3-factor 7: inconsistency and lack of coordination between the plans and maps of the contractor and the employer and the lack of human resources for wood design specialists, and 4-factor 11: delays in supply and poor quality of equipment and the materials under the employer's commitment. 


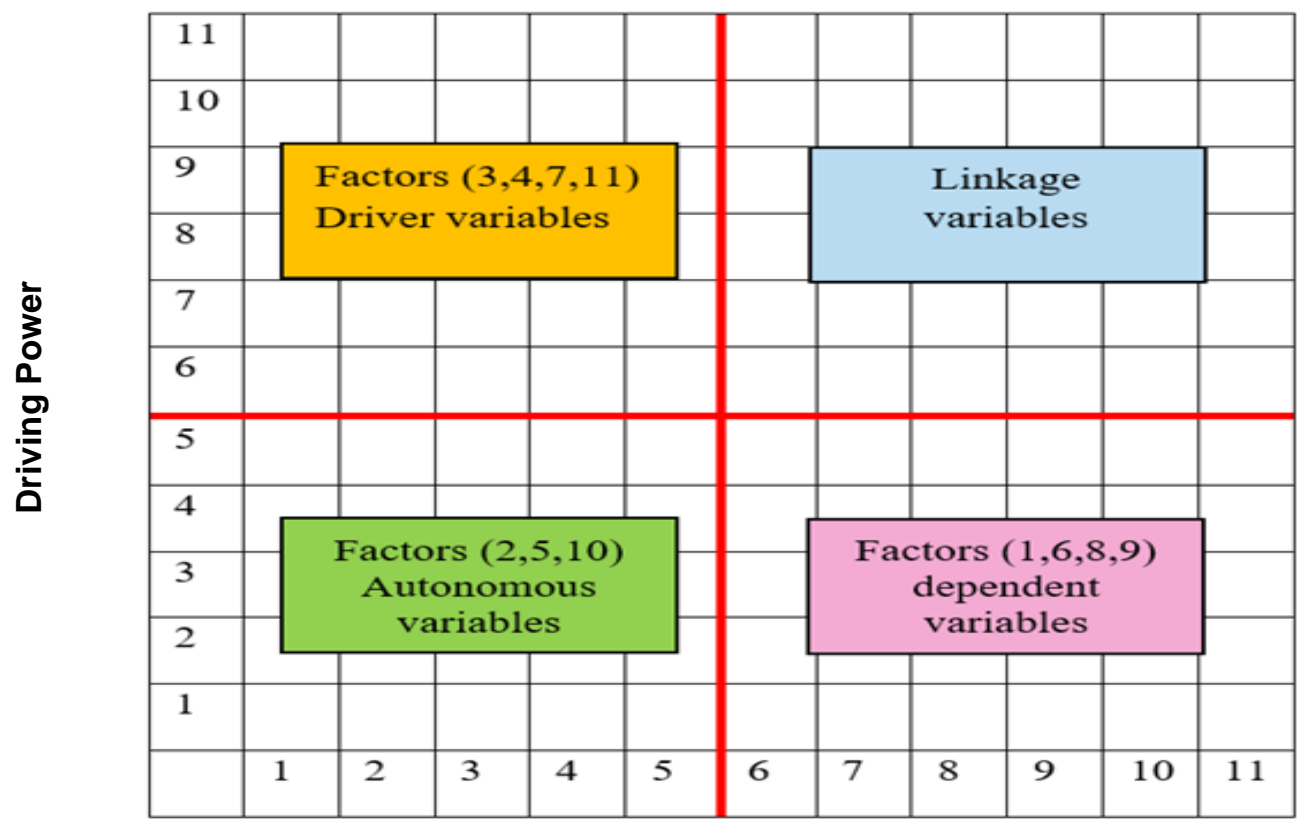

Dependence Power

Fig. 3. Driving and dependence power diagram for the suggested factors

\section{DISCUSSION}

Reducing danger to citizens requires a comprehensive system of dealing with crises by employing new global crisis management approaches that emphasize disaster risk reduction by reducing and addressing natural hazards as much as possible. In addition, creating an ideal living environment for resident wellbeing must be prioritized. There are many strategies to reduce risk and improve living environments, some of which are more important than others. For example, strategies such as utilizing new retrofitting technologies, accurate monitoring, controlling the execution operations of buildings, texture improvement and renovation, special attention to the role of open spaces and convenience, balancing the allocation of uses and establishing order between mass and space, increasing permeability in textures, preserving and promoting the social identity of the city, and coordination of management and relief agencies to reduce casualties after earthquakes are essential.

The results of this study revealed that the dimensions of the risk, which included the dimensions of internal risks (employer risk, implementation risk, scheduling risk, manpower risk, and design risk) and dimensions of external risk, such as risk due to political, economic, legal, and natural factors that are the most important risk factors in residential wooden structures in earthquake-prone areas of Iran. In earthquake-prone areas, the growth of light-weight construction is expected. Among the new technologies in industrial housing construction, the wooden system is the lightest. This is noteworthy, as the extent of damage due to earthquakes is a function of mass and acceleration, which naturally decreases when the mass of the building is lower. Wooden houses do not collapse entirely, and when they are broken by an earthquake or other event, they may break, and the pieces will not collapse. These findings are useful for academic staffs and graduate 
students in construction management and civil engineering professionals as well as related companies seeking to develop technology for the production of wooden residential structures.

According to the first level of research, which is the complexity of wooden structure construction and rework, the followings points are suggested:

- Presenting all drawings and execution details of the project immediately after concluding the contract to the contractors' representative and informing the workshop supervisors by briefings before and during the execution of the operation.

- Checking the work records and technical and professional skills of all supervisors and other leadership roles before concluding the contract.

According to the second level of research, which includes the lack of proper time planning wooden structure construction, failure to consider local regulations, codes and the issuance of permits, unpredictable physical conditions, and natural disasters, the following are recommended:

-Providing a detailed and comprehensive schedule before commencing projects by using qualified consultants and appropriate software for scheduling and accurate implementation of the program in different stages.

Based on the third level of research, which is the lack of control and supervision of development and changes in the scope of work of the construction project of wooden structures, the following is suggested:

-Identifying the objectives, scope of work, costs, volume of operations, schedule of the onset and outset of the project, and controlling and monitoring the development and changes in the scope of the project.

Considering the fourth level of research, which considers political pressures and sanctions (affecting procurement, financing, and employment of foreign laborers, etc.) and the occurrence of defects and flaws in the procurement of equipment for wooden structures, the following measures are suggested:

-Maximum use of resources and materials and domestic manpower to prevent work stoppage in the event of political crises.

-Avoiding economic sanctions by using accounting consultants and interior architecture designers and accepting the assistance of any foreign company in the design in the project.

According to the fifth level of research, which is the lack of consistency and coordination of the plans and maps of the contractor and the employer and the lack of human resources specialized in wood design, the following are suggested:

-Careful review of the work history of various consulting companies to select the best company for designing affairs

-Considering all the items requested by the employer (if applicable) in designing and justifying the submitted plans to the employer

According to the sixth level of the study, which consists of the lack of appropriate allocation of financial resources and budgets, changes in exchange rates and inflation, lack of manpower skills in the construction of wooden structures, delays in the supply of equipment, and poor quality of equipment and materials for which the employer is responsible, the following are recommended:

-Conducting an accurate and detailed needs assessment of the employer before starting the executive operation to minimize possible changes during the project.

-Estimating the exact financial costs of the project before starting the execution operation. 


\section{CONCLUSION}

In this paper, the authors introduce an ISM-based model of the factors that impact risk management in residential wooden structures in earthquake-prone areas of Iran. Iran has experienced numerous earthquakes in the past years, and this disaster natural likely will occur in future. Therefore, the construction of safe buildings is the main objective of engineers. For this purpose, one of the best building systems used is wood-frame houses. The final 11 factors were chosen based on the several questionnaire rounds and the opinion of experts and completely related to risk management in residential wooden structures in earthquake-prone areas of Iran. To create and direct complex relationships between the factors, the ISM methodology was used. It is important to note that the ISM method is a tool to identify the order and directions of the complexity of relationships among the system factors. The results showed that the related final factors are at the sex level of ISMbased level, in a way, the factor 6 (Complexity of wooden structure construction and rework) was at the level 1 and at the top level of the ISM hierarchy. Also the factor 3 (Failure to properly allocate financial resources and budgets and changes in exchange rates and inflation) was at the level 6 and the bottom level of the ISM hierarchy. In MICMAC analysis, the variables are divided into four categories based on driving power and dependence power, the type of variables is determined according to the impact on other variables, and influence of other variables. For instance, factor 3 is a key factor; therefore, any action on this factor causes to change other factors. In the case of factor 6 , many factors are involved in creating this factor, and this factor itself causes less change in other factors.

\section{REFERENCES CITED}

Abedini, A., and Karimi, R. (2018). "Assessment the seismic risk in Urmia city context based on fuzzy hierarchical process analysis method," Disaster Prevention and Management Knowledge 8(2), 149-160.

Ahmad, M., Tang, X. -W., Qiu, J.-N., and Ahmad, F. (2019). "Interpretive structural modeling and MICMAC analysis for identifying and benchmarking significant factors of seismic soil liquefaction," Applied Sciences 9(2), 233-254. DOI: 10.3390/app9020233

Aziznasiri, S., Sami Dariani, N., Ismaili, S. M. R., Rahimi, B., and Dehghani, H. (2017). "Earthquake risk management in residential buildings; proposal form and general conditions," in: Proceedings of the $24^{\text {th }}$ National Conference on Insurance and Development, Tehran, Iran, pp. 1-28.

Berge, B. (2009). The Ecology of Building Materials, $2^{\text {nd }}$ Ed., Routledge, Oxfordshire, England.

Calkins, M. (2009). Materials for Sustainable Sites: A Complete Guide to the Evaluation, Selection and Use of Sustainable Construction Materials, Wiley \& Sons, Hoboken, NJ, USA.

Dhir, S. (2020). "Modeling of strategic thinking enablers: A modified total interpretive structural modeling (TISM) and MICMAC approach," International Journal of System Assurance Engineering and Management 11(1), 175-188. DOI: 10.1007/s13198-019-00937-z

Ertas, A., Rohman, J., Chillakanti, P., and Batuhan Baturalp, T. (2015). "Transdisciplinary collaboration as a vehicle for collective intelligence: A case study 
of engineering design education," International Journal of Engineering Education 31(6), 1526-1536.

Faisal, M. N., Banwet, D. K., and Shankar, R. (2006). "Supply chain risk mitigation: Modeling the enablers," Business Process Management Journal 12(4), 535-552. DOI: $10.1108 / 14637150610678113$

Faisal, M. N., Banwet, D. K., and Shankar, R. (2007). "Quantification of risk mitigation environment of supply chains using graph theory and matrix methods," European Journal of Industrial Engineering 1(1), 22-39. DOI: 10.1504/EJIE.2007.012652

Gorzen-Mitka, I. (2019). "Interpretive structural modeling approach to analyze interaction among key factors of risk management process in SMEs: Polish Experience," European Journal of Sustainable Development 8(1), 339-349. DOI: 10.14207/ejsd.2019.v8n1p339

Govindan, K., Palaniappan, M., Zhu, Q., and Kannan, D. (2012). “Analysis of third party reverse logistics provider using interpretive structural modeling," International Journal of Production Economics 140(1), 204-211. DOI: 10.1016/j.ijpe.2012.01.043

Hillson, D. A. (2009). Managing Risk in Projects, Gower, Farnham, England.

Hillson, D. A. (2002). "Extending the risk process to manage opportunities," International Journal of Project Management 20(3), 235-240. DOI: 10.1016/S02637863(01)00074-6

Jharkharia, S., and Shankar, R. (2005). "IT enablement of supply chains: Modeling the enablers," International Journal of Productivity and Performance Management 53(8), 700-712. DOI: 10.1108/17410400410569116

Landeta, J. (2006). "Current validity of the Delphi method in social sciences," Technological Forecasting and Social Change 73(5), 467-482. DOI: 10.1016/j.techfore.2005.09.002

Li, Y., and Ellingwood, B. R. (2009). "Framework for multihazard risk assessment and mitigation for wood-frame residential construction," Journal of Structural Engineering 135(2), 159-168. DOI: 10.1061/(asce)0733-9445(2009)135:2(159)

Mandal, A., and Deshmukh, S. G. (1994). "Vendor selection using interpretive structural modeling (ISM)," International Journal of Operations \& Production Management 14(6), 52-59. DOI: 10.1108/01443579410062086

Parthiban, P., Zubar, A. H., and Garge, C. P. (2012). "A multi criteria decision making approach for suppliers selection," Procedia Engineering 38(2012), 2312-2328. DOI: 10.1016/j.proeng.2012.06.277

Powell, C. (2003). "The Delphi technique: Myths and realities," Journal of Advanced Nursing 41(4), 376-382. DOI: 10.1046/j.1365-2648.2003.02537

Purkus, A., Hagemann, N., Bedtke, N., and Gawel, E. (2018). "Towards a sustainable innovation system for the German wood-based bioeconomy: Implications for policy design," Journal of Cleaner Production 172, 3955-3968. DOI: 10.1016/j.jclepro.2017.04.146

Ravi, V., and Shankar, R. (2005). "Analysis of interactions among the barriers of reverse logistics," Technological Forecasting and Social Changes 72(8), 1011-1029. DOI: 10.1016/j.techfore.2004.07.002

Rowe, G., and Wright, G. 1999. "The Delphi technique as a forecasting tool: Issues and analysis," International Journal of Forecasting 15(4), 353-373. DOI: 10.1016/S01692070(99)00018-7

Sage, A. P. (1977). Interpretive Structural Modeling: Methodology for Large Scale Systems, McGraw-Hill, New York, NY, USA, pp. 91-164. 
Tan, T., Chen, K., Xue, F., and Lu, W. (2019). "Barriers to building information modeling (BIM) implementation in China's prefabricated construction: An interpretive structural modeling (ISM) approach," Journal of Cleaner Production 219, 949-959. DOI: 10.1016/j.jclepro.2019.02.141

van Teijlingen, E., Pitchforth, E., Bishop, C., and Russell, E. (2006). "Delphi method and nominal group technique in family planning and reproductive health research," Journal of Family Planning and Reproductive Health Care 32(4), 249-252. DOI: 10.1783/147118906778586598.

Van Thuyet, N., Ogunlana, S.O., and Dey, P. K. (2007). "Risk management in oil and gas construction projects in Vietnam," International Journal of Energy Sector Management 1(2), 175-194. DOI: 10.1108/17506220710761582

Warfield, J. N. (1974). "Developing interconnected matrices in structural modeling," IEEE Transcript on Systems, Men and Cybernetics 4(1), 51-81.

Warfield, J. N. (1990). A Science of Generic Design: Managing ComplexityThrough Systems Design, Intersystems Publications, Salinas, CA, USA.

Wu, W.-Sh., Yang, Ch.-F., Chang, J.-Ch., Chateau, P.A., and Chang,Y.-Ch. (2015). "Risk assessment by integrating interpretive structural modeling and Bayesian network, case of offshore pipeline project," Reliability Engineering and System Safety 142(C), 515-524. DOI: 10.1016/j.ress.2015.06.013.

Yeganeh, A., and Shariatmadar, S. H. (2017). "Technical note: Risk detection in light steel frame buildings in design, construction and implementation phases," Journal of Structural and Construction Engineering 4(4), 186-200. DOI:

10.22065/JSCE.2017.80905.1125

Article submitted: March 09, 2021; Peer review completed: May 31, 2021; Revised version received and accepted: August 22, 2021; Published: October 6, 2021.

DOI: $10.15376 /$ biores.16.4.7855-7869 